\title{
Oreocallis grandiflora Leaves Extract as a Natural Inhibitor for Protection of the Steel in Acid Solution
}

\section{AMES CANCHAYA HAROLD ${ }^{1}$, TUFINIO MIRANDA KAREN ${ }^{1}$, PAUCAR CUBA KARIN $^{1 *}$, VERGARA SOTOMAYOR ABEL ${ }^{1}$}

1. Corrosion Laboratory, Chemical Engineering and Textile Faculty. National Engineering University, Lima-Peru.

* Corresponding author: kpaucar@uni.edu.pe

Mild steel is one of the most used materials due to its low cost even though it could suffer aggressive corrosion in acid solutions. Aqueous acid solutions such as $\mathrm{HCl}$ are widely used in the pickling of the steel industry for this reason the importance of steel protection against acid attack. Natural corrosion inhibitors are an environmentally friendly alternative instead of synthetic inhibitors to effectively protect steel in acid solutions [1], [2].

The objective of the study was to evaluate the corrosion inhibition capacity of the ethanolic leaves extract of the Oreocallis grandiflora in $1 \mathrm{M} \mathrm{HCl}$ solution, through weight loss tests at inhibitor concentrations ranging from 62.5 to $625 \mathrm{ppm}$, immersion time from $1 \mathrm{~h}$ to $12 \mathrm{~h}$ and temperature in the range of $20^{\circ} \mathrm{C}$ to $50^{\circ} \mathrm{C}$. The corrosion inhibition effect is confirmed using micrographs and analyses EDS-SEM.

The Oreocallis grandiflora extract was obtained from the ground leaves in absolute ethanol at room temperature using the maceration with stirring method. Metallic specimens of size $4 \mathrm{~cm} \times 1 \mathrm{~cm} \times 0.1 \mathrm{~cm}$ with a small hole near the upper edge of the specimen were used for the determination of corrosion rate by the weight loss test, these specimens were mechanically polished using 80 to 1000 grade emery paper in water and degreased with ethanol before use. The initial weight of the metallic specimens was registered before being completely immersed into the acid solution in absence and presence of different concentrations of inhibitor and different immersion times. After the test, the specimens were taken out, the oxide remains were removed, washed with distilled water, dried completely and their final weights were registered to calculate the weight loss.

The results show that the increase in the concentration, from $250 \mathrm{ppm}$, of the inhibitor increases the inhibition efficiency, reaching values near to $90 \%$ at $20^{\circ} \mathrm{C}$ and the inhibition mechanism is associated with the adsorption of the inhibitor extract on the metal surface obeying the Langmuir isotherm. The increase of exposure time of the metal in the acid solution with inhibitor at 250ppm results in a higher efficiency, on the contrary, with 6 hours of immersion time at $30^{\circ} \mathrm{C}$, the inhibition efficiency is $86.57 \%$ and with the increase of temperature, the efficiency decreases. Therefore, ethanolic extract of Oreocallis grandiflora leaves works as an inhibitor of 1008 steel in $1 \mathrm{M} \mathrm{HCl}$ solutions at $20^{\circ} \mathrm{C}$ and $30^{\circ} \mathrm{C}$.

The SEM micrographs of the steel samples after immersion in $1 \mathrm{M} \mathrm{HCl}$ solution in the absence and presence of the inhibitor extract at $250 \mathrm{ppm}$ confirmed the presence of the inhibitor extract adsorbed on the metal surface and its lesser superficial damage while the EDS analyses of Fe content (\%Wt) of these samples confirmed the highest content of \% Fe in the steel sample exposed in $1 \mathrm{M} \mathrm{HCl}$ solution in the presence and absence of the natural inhibitor, $96.30 \%$ and $92.61 \%$, correspondingly (see Figures 1 and 2). 


\section{References:}

[1] J Gonzalez in "Control de la corrosión: Estudio y medida por técnicas electroquímicas”, ed. C.S.I.C., (Grafipen, Madrid) p.407.

[2] M Shyamala in "Plant extracts as corrosion inhibitors", ed. LAP LAMBERT, (Academic Publishing, Saarbrücken) p.86.

[3] The authors wish to acknowledge the CONCYTEC for financing the research project contract 155-2017-FONDECYT and Dr. Gladys Ocharan Velasquez for the support provided in obtaining micrographs and analysis EDS-SEM.

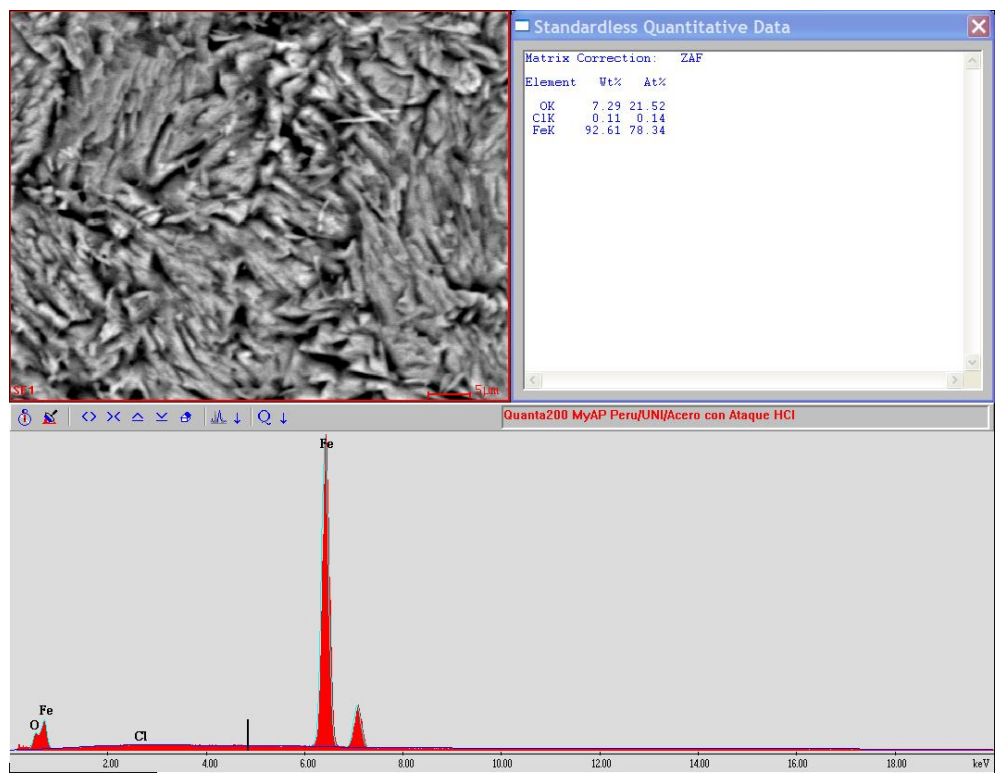

Figure 1. Micrograph and analysis EDS-SEM of 1008 steel surface in $1 \mathrm{M} \mathrm{HCl}$.

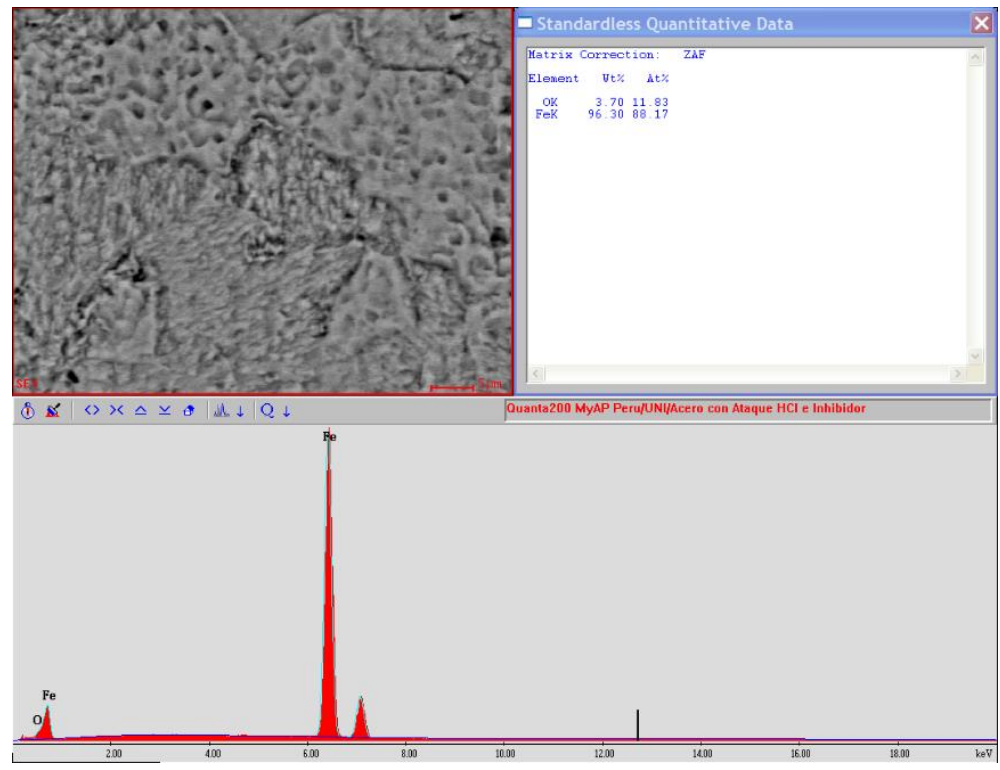

Figure 2. Micrograph and analysis EDS-SEM of 1008 steel surface in $1 \mathrm{M} \mathrm{HCl}$ containing $250 \mathrm{ppm}$ Oreocallis grandiflora inhibitor extract. 